\title{
Article \\ Orthodontic Treatment and Craniocervical Posture in Patients with Temporomandibular Disorders: An Observational Study
}

\author{
Maria Paço $^{1}$ (D) José Alberto Duarte ${ }^{2}$ a and Teresa Pinho ${ }^{1,3, * \mathbb{D}}$ \\ 1 CESPU, Instituto de Investigacão e Formação Avançada em Ciências e Tecnologias da Saúde, \\ 4585-116 Gandra-Paredes, Portugal; maria.paco@ipsn.cespu.pt \\ 2 CIAFEL, Faculdade de Desporto da Universidade do Porto, 4200-450 Porto, Portugal; jarduarte@fade.up.pt \\ 3 IBMC-Inst. Biologia Molecular e Celular, i3S-Inst. Inovação e Investigação em Saúde, \\ Universidade do Porto, 4585-116 Porto, Portugal \\ * Correspondence: teresa.pinho@iucs.cespu.pt
}

Citation: Paço, M.; Duarte, J.A.; Pinho, T. Orthodontic Treatment and Craniocervical Posture in Patients with Temporomandibular Disorders: An Observational Study. Int. J. Environ. Res. Public Health 2021, 18 , 3295. https://doi.org/10.3390/ ijerph18063295

Academic Editor: Gianrico Spagnuolo

Received: 25 February 2021

Accepted: 18 March 2021

Published: 23 March 2021

Publisher's Note: MDPI stays neutral with regard to jurisdictional claims in published maps and institutional affiliations.

Copyright: (c) 2021 by the authors. Licensee MDPI, Basel, Switzerland. This article is an open access article distributed under the terms and conditions of the Creative Commons Attribution (CC BY) license (https:// creativecommons.org/licenses/by/ $4.0 /)$.

\begin{abstract}
Orthodontic treatment acts through the application of forces and/or by stimulating and redirecting the functional forces within the craniofacial complex. Considering the interrelationship between craniomandibular and craniocervical systems, this intervention may alter craniocervical posture. Thus, our aim is to (a) compare craniocervical posture, hyoid bone position, and craniofacial morphology before, after, and also in the contention phase at least one year after the orthodontic treatment, in patients with temporomandibular disorders and (b) to verify whether the presence of condylar displacement, the skeletal class, or the facial biotype interferes with the abovementioned outcomes. To do so an observational, analytical, longitudinal, and retrospective design study was carried out. A non-probabilistic convenience sampling method was applied. The sample consisted of clinical records of patients diagnosed with temporomandibular disorders in order to compare pre-orthodontic treatment with post-orthodontic treatment $(n=42)$ and contention phase data $(n=26)$. A cephalometric analysis of several variables was performed. The $p$-value was set as 0.05 . When the pre- and post-orthodontic treatment data were analyzed, there were statistically significant changes in variables concerning craniocervical posture (CV angle, $\mathrm{C} 0-\mathrm{C} 1$, and AA-PNS) and also concerning hyoid bone position (C3-Rgn). When pre- and post-orthodontic treatment and contention phase data were analyzed the variables concerning craniocervical posture (C0-C1, CVT/Ver, NSL/OPT, NSL/CVT, NSL/Ver; OPT/CVT, OPT/Ver) and facial biotype had statistically significant changes. This allowed us to conclude that in the sample studied, there were significant differences regarding hyoid bone position (pre- versus post-orthodontic treatment) and craniocervical posture (pre- versus post-orthodontic versus contention), with the craniocervical posture being prone to return to basal values. The presence of condylar displacement was found to significantly increase the $\mathrm{H}-\mathrm{H} 1 \mathrm{distance}$ in the three moments of evaluation. Facial biotype was found to significantly increase the NSL/Ver angle on hypodivergent compared to hyperdivergent in the contention phase.
\end{abstract}

Keywords: cephalometry; cervical spine; posture

\section{Introduction}

"Although scientific studies do not strongly link orthodontic therapy with the development or prevention of TMD (temporomandibular disorders), it is difficult to imagine a specialty that routinely and significantly changes a patient's occlusal condition would not have a powerful effect on the masticatory structures and their functions" [1]. This was pointed out by Okeson, and reflects some of the controversies regarding the effects of orthodontic treatment on TMDs [2-13]. Though some studies identify small associations between orthodontics and TMDs, they fail to isolate a single unique aspect that can either refute or support this association [3]. One of the possible explanations to these controversial results is the heterogeneity of TMDs, a multifactorial entity without a well-defined etiopathogenesis [14-19] that encompasses several conditions, such as temporomandibular 
joint pain, mastication muscle pain, or a combination of both [15-17,20,21]. Having this, when there is a need for orthodontic treatment to target malocclusion $[2,3,22,23]$ concomitant to TMDs, the clinician should be aware of signs and symptoms associated with TMDs and adjust the clinical management before and during the orthodontic treatment [24].

Moreover, the close relationship between the craniomandibular and craniocervical systems has been described, showing their functional, biomechanical, neurodynamic, and physiological interrelationship as both having the potential to influence each other reciprocally [25-38]. Taking this into account, it seems possible that the mechanical effects from orthodontics may lead to muscular and articular adaptations on the cervical spine. Furthermore, considering that a craniocervical dysfunction may act as a contributing factor to TMDs $[15,25,26,28,36-49]$, it is reasonable to assume that the clinician should evaluate any change in the craniocervical region during orthodontic treatment, as well as any change in the TMDs complaints.

Thus, since the relationship between orthodontic treatment and craniocervical posture has not been fully addressed so far, the main objective of this study was to compare craniocervical posture, hyoid bone position, and craniofacial morphology before and after orthodontic treatment and also in the contention phase in patients with TMDs. A secondary objective was to verify whether the presence of condylar displacement, the skeletal class, or the facial biotype interfere with the abovementioned outcomes.

\section{Materials and Methods}

\subsection{Study Design}

This was an observational, analytical, longitudinal, and retrospective design. A nonprobabilistic convenience sampling method was applied, accessing clinical documentation from patients that were submitted to orthodontic treatment and had a clinical diagnose of TMDs. The sample consisted of clinical records of 42 patients treated by the same specialist and $\mathrm{PhD}$ in orthodontics (Pinho, T.) to compare pre-orthodontic treatment to post-orthodontic treatment. From this initial sample a sub-group of 26 clinical records (that contained a teleradiograph from one year after orthodontic treatment) was analyzed in order to compare pre- and post-orthodontic treatment and contention phase data.

To be included in the study the patients had to be examined for clinical history (clinical diagnosis of TMDs, based on Diagnostic Criteria for Temporomandibular DisordersDC/TMD), lateral and anterior photographs (in a natural head position), have goodquality teleradiography (also in natural head position and should include the head and cervical column, with at least the fourth cervical vertebra completely visible), have dental casts mounted on an articulator in a centric relation, and be aged at the beginning of orthodontic treatment between 18 and 50 years old. Another inclusion criterion was the achievement of a canine Class I relation and normalized overjet and overbite values after orthodontic treatment.

Cases were excluded if they presented history of traumatic injuries, fibromyalgia syndrome, diagnosis of systemic disease, or presence of neurological disorders.

Ethical approval was guaranteed by the Ethics Committee at Instituto Universitário de Ciências da Saúde, CESPU (3/CE-IUCS/2016).

\subsection{Procedures}

After checking the eligibility of the cases, the assessment of craniocervical posture, hyoid bone position, craniofacial morphology, and occlusal factors was performed.

The occlusal parameter studied was the presence of malocclusions and condylar displacement, using intra-oral photographs as well as dental casts. Furthermore, the mounting models were adopted in a centric relation on a semi-adjustable articulator SAM $3^{\circledR}$ (Präzisionstechnik, Taxisstr. 41, München, Germany) and the register of the condyle position and consequently the amount of condylar displacement was registered with a mandible position indicator (MPI $120^{\circledR}$, Präzisionstechnik, Taxisstr. 41, München, Germany). These procedures were previously described and considered reliable [50-52]. 
When the condylar displacement was analyzed, it was considered that a $\Delta \geq 2 \mathrm{~mm}$ was consistent with a higher risk of developing TMDs, and the participants were classified as "condylar displacement present" [23,53-57].

Regarding the craniocervical posture, hyoid bone position, and craniofacial morphology analyses, these were performed by teleradiograph cephalometric analysis with lateral photograph superimposition (both in a natural head position) with Nemoceph ${ }^{\circledR}$ software (Nemoceph 6-Dental Studio NX, version 6.0, Madrid, Spain) ${ }^{\circledR}$. The method for obtaining the lateral cephalogram in a natural head position was performed as previously described [58] and the lateral photographs (also in a natural head position) used for superimposition allowed for the confirmation of a natural head position.

A natural head position was obtained following the procedures established in the literature. The cephalometric points used were marked as previously described [59-64] and are defined in Table 1.

Table 1. Cephalometric landmarks, angles, and reference measures.

\begin{tabular}{|c|c|}
\hline Measure & Definition \\
\hline Craniovertebral angle (CV angle) & $\begin{array}{l}\text { The angle resulting from the intersection between a horizontal line that goes from the Bolton point (Bo) } \\
\text { (the intersection of the outline of the occipital condyle and the foramen magnum at the highest point on } \\
\text { the notch posterior to the occipital condyle) to the posterior nasal spine and the vertice of the odontoid } \\
\text { process and the anteroinferior point of the odontoid process. }\end{array}$ \\
\hline $\mathrm{C} 0-\mathrm{C} 1$ & $\begin{array}{l}\text { The distance between the horizontal line that goes from the posterior nasal spine and the most anterior } \\
\text { point of the first cervical vertebra. }\end{array}$ \\
\hline $\mathrm{C} 1-\mathrm{C} 2$ & $\begin{array}{l}\text { The distance between the most anterior aspect of the first cervical vertebra and the second } \\
\text { cervical vertebra. }\end{array}$ \\
\hline $\mathrm{C} 3-\mathrm{H}$ & $\begin{array}{l}\text { The distance between the most anterior aspect of the third cervical vertebra and the most anterior point } \\
\text { of the hyoid bone. }\end{array}$ \\
\hline C3-Rgn & $\begin{array}{l}\text { The distance between the most anterior aspect of the third cervical vertebra and the most dorsal and } \\
\text { inferior point of mandibular symphysis (retrognation). }\end{array}$ \\
\hline H-H1 & $\begin{array}{l}\text { The distance from the most anterior point of the hyoid bone and the horizontal line that goes from the } \\
\text { most anterior aspect of the third cervical vertebra and retrognation. }\end{array}$ \\
\hline H-Rgn & The distance from the most anterior point of the hyoid bone and the retrognation. \\
\hline AA-PNS & The distance from the most anterior point of the atlas vertebra (AA) to the posterior nasal spine. \\
\hline $\mathrm{CVT} / \mathrm{Ver}$ & $\begin{array}{l}\text { The angle resulting from the intersection between the tangent that goes posterior to the odontoid } \\
\text { process through the most posterior and inferior aspect of the fourth cervical vertebra body and the } \\
\text { vertical line that corresponds to the true vertical. }\end{array}$ \\
\hline NSL/CVT & $\begin{array}{l}\text { The angle resulting from the intersection between a line that goes from the sela turcica to the nasion } \\
\text { and the tangent that goes posterior to the odontoid process through the most posterior and inferior } \\
\text { aspect of the fourth cervical vertebra body. }\end{array}$ \\
\hline NSL/OPT & $\begin{array}{l}\text { The angle resulting from the intersection between a line that goes from the sela turcica to the nasion } \\
\text { and the tangent that goes posterior to the odontoid process through the most posterior and inferior } \\
\text { aspect of the second cervical vertebra body. }\end{array}$ \\
\hline NSL/Ver & $\begin{array}{l}\text { The angle resultant from the intersection between a line that goes from the sela turcica to the nasion and } \\
\text { the vertical line that corresponds to the true vertical. }\end{array}$ \\
\hline OPT/CVT & $\begin{array}{l}\text { The angle resulting from the tangent that goes posterior to the odontoid process through the most } \\
\text { posterior and inferior aspect of the second cervical vertebra body and the tangent that goes posterior to } \\
\text { the odontoid process through the most posterior and inferior aspect of the fourth cervical vertebra body. }\end{array}$ \\
\hline OPT/Ver & $\begin{array}{l}\text { The angle resulting from the intersection between the tangent that goes posterior to the odontoid } \\
\text { process through the most posterior and inferior aspect of the second cervical vertebra body and the } \\
\text { vertical line that corresponds to the true vertical. }\end{array}$ \\
\hline Facial biotype & $\begin{array}{l}\text { Through the measurement of FMA, where a score less than } 22 \text { means hypodivergent, between } 22 \text { and } \\
28 \text { means normodivergent, and higher than } 28 \text { means hyperdivergent. }\end{array}$ \\
\hline Skeletal class & $\begin{array}{l}\text { Through the measurement of ANB, where a score inferior to } 0 \text { represents Class III, between 0-5 } \\
\text { represents Class I, and a score superior to } 5 \text { represents Class II. }\end{array}$ \\
\hline Facial proportion & Calculated by the intersection ratio of the Sn-Gnc line with the Gnc-C line. \\
\hline
\end{tabular}

Lateral cephalograms of 10 randomly selected subjects were measured twice, with a one-week interval between measurements, to assess the magnitude of measurement errors 
(intraclass correlation coefficient $\left.(\mathrm{ICC})_{(2,1)}\right)$. The $\operatorname{ICC}_{(2,1)}$ for the reliability of the landmark identification was 0.98 , demonstrating an excellent reliability [65].

\subsection{Statistical Analysis}

Statistical analysis was performed using the Statistical Package for the Social Sciences (SPSS) ${ }^{\circledR}$, version 24 (IBM, Chicago, IL, USA). To assess the normal distribution of the variables, the Shapiro-Wilk test was applied. Sample characteristics are presented as absolute frequencies in categorical variables and mean and standard deviation (SD) in quantitative variables. The presence of potential differences between pre- and post-intervention results were analyzed through a paired samples $t$-test or Wilcoxon test, respectively, for whether the outcomes had a normal distribution or not. A repeated-measures ANOVA was used to evaluate the presence of potential differences between the three assessment moments (preintervention, post-intervention, and contention phase). The assumptions to perform this test were normal distribution of the variables (Shapiro-Wilk test) and sphericity (Mauchly's test). When the sphericity assumption was not fulfilled, the F-value was corrected, in accordance with previously described methods [66]. Multiple comparisons between the three assessment moments were performed through a Bonferroni post-hoc test. When the assumptions for parametric tests were not fulfilled, the Friedman test was used, and multiple comparisons were performed through Wilcoxon tests. To compare the outcome variables, according to the presence or absence of condylar displacement, independent samples $t$-tests or Mann-Whitney tests were used as parametric and non-parametric tests, respectively. To compare the outcome variables according to the skeletal class and facial biotype, the one-way ANOVA (with a Bonferroni post-hoc test) and Kruskal-Wallis tests were used as parametric and non-parametric tests, respectively. The critical value for significance in all the analysis was $p$-value $<0.05$.

\section{Results}

The sample regarding pre and post orthodontic treatment results consisted of 42 individuals (6 men, 36 women), aged $28.14 \pm 11.36$ years in the beginning of the treatment and the duration of orthodontic treatment was $2.87 \pm 1.45$ years.

Data regarding facial and skeletal characteristics of the participants and pre-orthodontic treatment are presented in Table 2.

Table 2. Sample characterization regarding skeletal class, facial biotype, and condylar displacement before orthodontic treatment $(n=42)$.

\begin{tabular}{ccc}
\hline \multirow{2}{*}{ Characteristics } & Frequency (\%) \\
\hline \multirow{3}{*}{ Skeletal Class } & Skeletal Class I & 45.2 \\
& Skeletal Class II & 50 \\
& Skeletal Class III & 4.8 \\
\hline \multirow{2}{*}{ Facial Biotype } & Hypodivergent & 16.7 \\
& Normodivergent & 23.8 \\
& Hyperdivergent & 59.5 \\
\hline \multirow{2}{*}{ Condylar Displacement } & Present & 23.8 \\
& Absent & 76.2 \\
\hline
\end{tabular}

Table 3 presents the variables that had statistically significant changes when comparing the values for pre-orthodontic treatment to the values for post-orthodontic treatment.

When the cephalometric variables were adjusted to the presence or absence of condylar displacement, to the skeletal class, and also to the facial biotype, there were no significant differences among the different groups in any of the assessment moments, except for the variable H-Rgn, with differences between skeletal Class I (43.69 \pm 4.33$)$ and Class II $(39.72 \pm 5.55)$ after orthodontic treatment $(p=0.009)$. 
Table 3. Cephalometric variables at two moments: pre-orthodontic treatment and post-orthodontic treatment $(n=42)$.

\begin{tabular}{|c|c|c|c|}
\hline Cephalometric Variable & Pre OT Mean (SD) & Post OT Mean (SD) & $p$-Value (Paired Samples $t$-Test) \\
\hline \multicolumn{4}{|l|}{ Craniocervical Posture } \\
\hline CV angle & $99.90(11.65) *$ & $98.10(13.00)^{*}$ & $0.036^{\dagger}$ \\
\hline $\mathrm{C} 0-\mathrm{C} 1$ & $6.75(4.01)$ & $7.84(3.96)$ & 0.017 \\
\hline $\mathrm{C} 1-\mathrm{C} 2$ & $20.15(2.18)$ & $20.80(2.35)$ & NS \\
\hline CVT/Ver & $7.42(7.32)$ & $7.38(8.07)$ & NS \\
\hline NSL/OPT & $78.50(15.25) *$ & $78.30(9.30) *$ & NSt \\
\hline NSL/CVT & $92.94(7.45)$ & $95.34(8.22)$ & NS \\
\hline NSL/Ver & $79.67(4.30)$ & $77.26(4.49)$ & NS \\
\hline $\mathrm{OPT} / \mathrm{CVT}$ & $15.72(4.80)$ & $15.10(4.54)$ & NS \\
\hline OPT/Ver & $23.14(9.21)$ & $22.48(10.64)$ & NS \\
\hline AA-PNS & $36.53(4.35)$ & $35.61(4.41)$ & 0.009 \\
\hline \multicolumn{4}{|l|}{ Hyioid Bone Position } \\
\hline $\mathrm{C} 3-\mathrm{H}$ & $36.60(3.92)$ & $36.98(4.36)$ & NS \\
\hline C3-Rgn & $74.70(8.49)$ & $76.80(7.84)$ & 0.018 \\
\hline $\mathrm{H}-\mathrm{H} 1$ & $5.11(6.14)$ & $4.31(6.04)$ & NS \\
\hline H-Rgn & $40.15(6.46)$ & $41.26(5.42)$ & NS \\
\hline \multicolumn{4}{|l|}{ Craniofacial Morphology } \\
\hline Facial biotype & $28.68(7.10)$ & $29.02(7.12)$ & NS \\
\hline Skeletal class & $4.88(3.03)$ & $5.11(3.02)$ & NS \\
\hline Facial proportion & $1.50(0.30)$ & $1.46(0.28)$ & NS \\
\hline
\end{tabular}

${ }^{*}$ Median (interquartile range); ${ }^{+}$Wilcoxon test; SD—standard deviation; OT—orthodontic treatment; NS—non-significant.

When the subgroup of participants with data regarding the contention phase was analyzed, the total number of participants was 26 ( 4 men, 22 women), aged $27.77 \pm 8.49$ years old at the beginning of the treatment.

Table 4 presents the variables that had statistically significant changes, when comparing pre-orthodontic treatment to post-orthodontic treatment and tothe contention phase.

When the cephalometric variables were adjusted to the presence or absence of condylar displacement, to the skeletal class, and also to the facial biotype, there were no differences among the different groups in any of the assessment moments, except for the variables H_H1, facial proportion, and NSL/Ver. H_H1 was found to have statistically significant changes between the participants with condylar displacement and those without it before orthodontic treatment ("condylar displacement present" $8.41 \pm 3.80$; "condylar displacement absent" $2.62 \pm 6.24 ; p=0.031$ ), after orthodontic treatment ("condylar displacement present" $7.63 \pm 2.97$; "condylar displacement absent" $2.14 \pm 7.10 ; p=0.11$ ), and in the contention phase ("condylar displacement present" $8.16 \pm 5.57 ;$; condylar displacement absent" $1.28 \pm 6.66 ; p=0.023$ ).

NSL/Ver was found to have statistically significant changes between hyperdivergent $(74.81 \pm 3.59)$ and hypodivergent facial type participants $(82.00 \pm 2.72)$ only in the contention phase $(p=0.005)$. 
Table 4. Cephalometric variables at three moments: pre-orthodontic treatment (Pre-OT), post-orthodontic treatment (Post-OT), and contention $(n=26)$, and respective $p$-values.

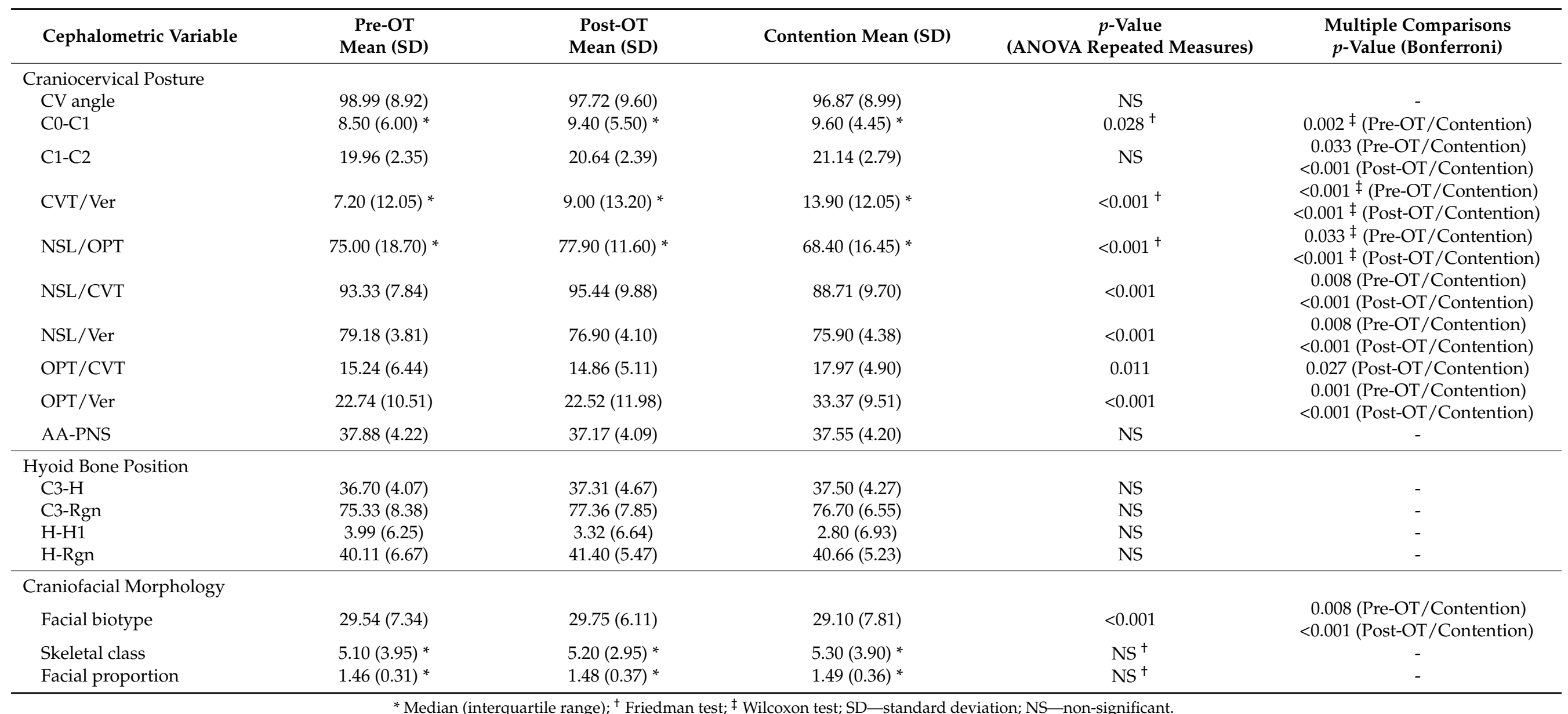




\section{Discussion}

In our study we evaluated the craniocervical posture in participants with a TMDs diagnose who underwent orthodontic treatment. Our participants were mostly hyperdivergent, with a skeletal Class II and a facial proportion that showed an increase in the inferior facial height and a decrease in the submandibular distance. The values of the facial proportion $(>1.20)$ showed a tendency toward Class II with posterior mandible rotation/retrusion, which is indicative of a weak musculature [61].

Our study showed that, after orthodontic treatment, the participants presented an increase in CV angle concomitantly with an increase in C0-C1 distance and in C3-Rgn distance, as well as a decrease in AA-PNS distance. An increase in CV angle is associated with an anterior rotation of the head [67]. This rotation of the head was also corroborated by the decrease in AA-PNS distance, which is usually associated with a flexed craniocervical posture. This finding was also confirmed by the results of the distance of $\mathrm{C} 0-\mathrm{C} 1$, the increase in which reflects the rectification of the cervical column. The increase in the C3-Rgn distance is also compatible with a loss of cervical lordosis. In spite of the variables NSL/OPT and NSL/CVT not presenting statistically significant changes, they did present relevant mean increases, which is also compatible with an anterior rotation of the head.

After adjustment of the cephalometric variables according to the presence or absence of condylar displacement, the skeletal class, and the facial biotype, the results showed that the presence of condylar displacement was found to significantly increase the $\mathrm{H}-\mathrm{H} 1$ distance at the three moments of evaluation compared to the participants without condylar displacement. This distance increase is associated with a downward position of the hyoid bone and may reflect muscular asymmetry between supra and infra-hyoid muscles. Facial biotype was found to significantly increase the NSL/Ver angle in hypodivergent compared to hyperdivergent participants in the contention phase. This result is compatible with a posterior rotation of the head and a forward inclination of the cervical column, which seems to be related to a hyperdivergent morphology and retrognathic profile.

This study also intended to assess the stability of the results obtained and did so by evaluating the presence of TMD signs and/or symptoms, the craniocervical posture, hyoid bone position, and craniofacial morphology (including dental class and overbite and overjet values) in the contention phase (one year after finishing orthodontic treatment) and comparing to pre-orthodontic treatment and post-orthodontic treatment data. This comparison was performed in a subgroup of the initial sample. When the results obtained were analyzed, all the patients remained TMD sign and symptom free, had no relapse in dental class, and overbite and overjet values remained within normal values.

On the other hand, significant changes were found mainly in the craniocervical posture variables and also in the facial biotype, which demonstrated a tendency toward normodivergence. The craniocervical posture variables that had statistically significant changes (C0-C1, CVT/Ver, NSL/OPT, NSL/CVT, NSL/Ver, OPT/CVT, OPT/Ver) had differences compatible with a posterior rotation of the head and an extended cervical column that highlights an increase in cervical lordosis, which is thought to increase the load on the posterior cervical structures [35], where an excessive capsular ligament stretch, beyond the biophysical limitations, could decrease the threshold of nerve endings and activate proprioceptors in facet joint capsules, which have a role in the development of cervical muscle pain [68]. These differences had a particular impact when "pre-orthodontic treatment" versus "contention phase" and "post orthodontic treatment" versus "contention phase" were analyzed. It was interesting to observe that in the majority of the measures that had significant changes (NSL/OPT, NSL/CVT, OPT/CVT, OPT/Ver), when "pre orthodontic treatment" versus "post orthodontic treatment" were compared the tendency shown was the opposite (anterior rotation of the head and rectification of the cervical column, although without statistically significant differences).

Keeping in mind the results found for the interrelationship between craniomandibular and craniocervical systems and considering the fact that the literature showed the shared pathophysiological mechanisms between TMDs and cervical spine disorders with cranio- 
cervical dysfunction having the potential to lead to or perpetuate TMDs [42-48], it is conceivable that craniocervical changes have the potential to contribute to the occlusal and/or TMD symptom relapse seen in clinical practice and described in the literature $[69,70]$.

The reduced sample size was the result of our inclusion criterion regarding the presence of TMDs. This fact allowed us to be more specific regarding TMD sufferers; however, it narrowed the sample that we had access to. Furthermore, it did not allow us to analyze the data according to TMD classification, which could have interfered with our results interpretation. Different types of TMDs have different clinical characteristics and may have interfered with the outcomes studied. However, despite the sample size, the effect sizes are important. Another factor to bear in mind is that the diagnosis of TMDs was a clinical diagnosis based on DC/TMD. This choice was due to the fact that during data collection the DC/TMD was not available in Portuguese (Portugal). It is also important to highlight the controversy regarding orthodontics and TMDs, with studies reporting good results on TMDs resolution or, at least, on reducing the risk of patients developing it, whereas other studies suggest that orthodontic treatment increases the risk of onset of signs and symptoms of TMDs or is TMD neutral [2,4-11]. In our study, and due to its methodological design, we did not aim to establish any causal relation between orthodontics and TMDs nor craniocervical posture, but rather to characterize the craniocervical posture before and after orthodontic treatment and also in the contention phase in patients with TMDs. Another factor to take into account is the evaluation of head and neck posture, which was performed in a resting position (natural head position). This is the position often used not only in research but also in clinical settings. However, considering that all individuals assume many different head and neck postures throughout their daily tasks, future studies should account for the dynamics of the cervical spine instead of focusing on rest positions, as suggested by Kraus [71].

Regarding the orthodontic treatment plan of our sample, it was performed taking into account the dental problems as well as the TMD condition. Although it has been established that orthodontic therapy neither causes nor prevents TMDs [11], this therapeutic intervention provides dental and orthopedic stability in the masticatory structures, which will most likely reduce the patient's risk factors for developing TMDs [72]. Concerning occlusal changes, mispositioned teeth associated with some malocclusions with steeper occlusal planes, posterior prematuries, and mandibular lateral displacement are often associated with craniomandibular dysfunction [73-75]. Having this, before planning orthodontic treatment, it is imperative to identify the location of an asymmetry, as treatment protocols will vary depending on the underlying etiology $[76,77]$. A midline discrepancy is one of the symptoms of mandibular lateral displacement and the major objective of orthodontic correction should be the elimination of any posterior discrepancy and the differential control of the occlusal plane. Therefore, by increasing the occlusal vertical height of the shifted or affected side, balanced muscle and articular disc positions can be restored, which is expected to contribute to the patient's TMD symptom resolution [74]. Furthermore, orthodontic treatment is aimed at controlling the occlusal plane, with consequent improvement of occlusal and articular functions $[73,75,78]$. Since occlusal factors may be a potential source of TMDs, improving occlusion will certainly minimize any risk factors that might be associated with TMDs [72].

In the present study, in the cases where the patients remained with a clinical diagnosis of TMDs after orthodontic treatment $(n=3 ; 7.14 \%)$, they were further evaluated by a specialist in orofacial pain who provided the treatment needed to specifically address this clinical condition.

It is also important to highlight the fact that, in our sample, six participants $(14,29 \%)$ had a loss of posterior teeth and, in these cases, the major objective of orthodontic correction was the elimination of any posterior discrepancy and the differential control of the occlusal plane [73]. The reader should bear in mind this fact, since this could potentially affect the facial morphology and the head and neck posture. 
Because there are no standardized values for most of the variables studied, we did not intend to classify the final result as normal or abnormal alterations, but mostly to characterize and verify whether there were changes after orthodontic treatment and in the contention phase. The presence of changes was interpreted as a signal of the interrelationship between craniomandibular and craniocervical systems, alerting the clinician to the necessity of addressing these alterations during the treatment and contention phase, since they may contribute to the development/aggravation of TMDs signs and/or symptoms, and also acknowledging that during orthodontic treatment other factors that interfere with general health status and quality of life may change. This monitoring is important since several studies have shown that an altered craniocervical posture seems to influence the process of myofascial pain sensitization in the cervical muscles, which could lead to the development of the referenced pain in the masticatory muscles $[46,63,79,80]$. Moreover, a recent systematic review and meta-analysis found that there was a significant correlation with a moderate clinical effect between neck disability and jaw disability in patients with TMDs [40]. In addition, a recent review by Gil-Martínez et al. [39] reported that neck disability was a strong predictor of craniofacial pain and disability in a subgroup of patients with TMDs due to muscle pain and that neck disability has a positive correlation with orofacial pain and disability, kinesiophobia, and pain catastrophizing.

In a clinical perspective, this knowledge about postural adaptations during orthodontic treatment should create awareness in the medical community, highlighting possible impairments that should be evaluated in order to achieve the greatest results for the patient.

Thus, it seems important to conduct well-designed longitudinal and randomized controlled trials comparing craniocervical posture as well as TMD signs and symptoms before and after the orthodontic treatment and a follow-up period superior to the contention phase (one year) in individuals diagnosed with TMDs, stratified according to TMD classification system.

\section{Conclusions}

Our results demonstrated that in the sample studied there were statistically significant differences regarding hyoid bone position (pre orthodontic treatment versus post orthodontic treatment) and craniocervical posture (between the three moments of evaluation: pre-orthodontic treatment, post-orthodontic treatment, and contention phase), with the craniocervical posture being prone to return to basal values. The presence of condylar displacement was found to significantly increase the $\mathrm{H}-\mathrm{H} 1$ distance in the three moments of evaluation. Facial biotype was found to significantly increase the NSL/Ver angle in hypodivergent compared to hyperdivergent participants in the contention phase.

Author Contributions: Conceptualization, M.P. and T.P.; methodology, M.P., T.P., and J.A.D.; data collection, M.P. and T.P.; statistical analysis, M.P. writing—original draft preparation, M.P.; writingreview and editing, M.P., T.P., and J.A.D.; supervision, T.P. and J.A.D.; funding acquisition, T.P. All authors have read and agreed to the published version of the manuscript.

Funding: This research was funded by IINFACTS-Institute of Research and Advanced Training in Health Sciences and Technologies (OrthoAlign-PI-4RL-IINFACTS-2019) and by FCT-Fundação para a Ciência e Tecnologia (FCT 02/SAICT/2017).

Institutional Review Board Statement: The study was conducted according to the guidelines of the Declaration of Helsinki and approved by the by the Ethics Committee at Instituto Universitário de Ciências da Saúde, CESPU (3/CE-IUCS/2016).

Informed Consent Statement: Informed consent was obtained from all subjects involved in the study.

Conflicts of Interest: The authors declare no conflict of interest. 


\section{References}

1. Okeson, J.P. Orthodontic therapy and temporomandibular disorders: Should the orthodontist even care? In Temporomandibular Disorders and Orofacial Pain: Separating Controversy from Consensus; McNamara, J.A., Jr., Kapila, S.D., Eds.; Department of Orthodontics and Pediatric Dentistry, School of Dentistry: Center for Human Growth and Development: Ann Arbor, MI, USA, 2009; pp. 15-29.

2. Imai, T.; Okamoto, T.; Kaneko, T.; Umeda, K.; Yamamoto, T.; Nakamura, S. Long-term follow-up of clinical symptoms in TMD patients who underwent occlusal reconstruction by orthodontic treatment. Eur. J. Orthod. 2000, 22, 61-67. [CrossRef]

3. Luther, F.; Layton, S.; McDonald, F. Orthodontics for treating temporomandibular joint (TMJ) disorders. Cochrane Database Syst. Rev. 2016, CD006541. [CrossRef]

4. Luther, F. TMD and occlusion part I. Damned if we do? Occlusion: The interface of dentistry and orthodontics. Br. Dent. J. 2007, 202, E2. [CrossRef] [PubMed]

5. Egermark, I.; Blomqvist, J.E.; Cromvik, U.; Isaksson, S. Temporomandibular dysfunction in patients treated with orthodontics in combination with orthognathic surgery. Eur. J. Orthod. 2000, 22, 537-544. [CrossRef]

6. Egermark, I.; Carlsson, G.E.; Magnusson, T. A prospective long-term study of signs and symptoms of temporomandibular disorders in patients who received orthodontic treatment in childhood. Angle Orthod. 2005, 75, 645-650.

7. Nielsen, L.; Melsen, B.; Terp, S. TMJ function and the effects on the masticatory system on 14-16-year-old Danish children in relation to orthodontic treatment. Eur. J. Orthod. 1990, 12, 254-262. [CrossRef] [PubMed]

8. Olsson, M.; Lindqvist, B. Mandibular function before and after orthodontic treatment. Eur. J. Orthod. 1995, 17, 205-214. [CrossRef] [PubMed]

9. Henrikson, T.; Nilner, M.; Kurol, J. Symptoms and signs of temporomandibular disorders before, during and after orthodontic treatment. Swed. Dent. J. 1999, 23, 193-207. [PubMed]

10. Leite, R.A.; Rodrigues, J.F.; Sakima, M.T.; Sakima, T. Relationship between temporomandibular disorders and orthodontic treatment: A literature review. Dent. Press J. Orthod. 2013, 18, 150-157. [CrossRef] [PubMed]

11. Manfredini, D.; Stellini, E.; Gracco, A.; Lombardo, L.; Nardini, L.G.; Siciliani, G. Orthodontics is temporomandibular disorderneutral. Angle Orthod. 2015, 86, 649-654. [CrossRef]

12. Mohlin, B.; Axelssonm, S.; Paulin, G.; Pietilä, T.; Bondemark, L.; Brattström, V. TMD in Relation to Malocclusion and Orthodontic Treatment: A Systematic Review. Angle Orthod. 2007, 77, 542-548. [CrossRef]

13. Macfarlane, T.V.; Kenealy, P.; Kingdon, H.A.; Mohlin, B.O.; Pilley, J.R.; Richmond, S.; Shaw, W.C. Twenty-year cohort study of health gain from orthodontic treatment: Temporomandibular disorders. Am. J. Orthod. Dentofac. Orthop. 2009, 135, 692.e1-692.e8. [CrossRef]

14. Stegenga, B. Nomenclature and classification of temporomandibular joint disorders: Classification of TMDS. J. Oral Rehabil. 2010, 37, 760-765. [CrossRef] [PubMed]

15. Leeuw, R.; de Klasser, G.D. Orofacial Pain: Guidelines for Assessment, Diagnosis, and Management, 6th ed.; Quintessence Publishing Co, Inc.: Hanover Park, IL, USA, 2018.

16. Cairns, B.E. Pathophysiology of TMD pain—Basic mechanisms and their implications for pharmacotherapy. J. Oral Rehabil. 2010, 37, 391-410. [CrossRef] [PubMed]

17. Ohrbach, R.; Bair, E.; Fillingim, R.B.; Gonzalez, Y.; Gordon, S.M.; Lim, P.-F.; Ribeiro-Dasilva, M.; Diatchenko, L.; Dubner, R.; Greenspan, J.D.; et al. Clinical Orofacial Characteristics Associated with Risk of First-Onset TMD: The OPPERA Prospective Cohort Study. J. Pain 2013, 14, T33-T50. [CrossRef]

18. Ohrbach, R.; Fillingim, R.B.; Mulkey, F.; Gonzalez, Y.; Gordon, S.; Gremillion, H.; Lim, P.-F.; Ribeiro-Dasilva, M.; Greenspan, J.D.; Knott, C.; et al. Clinical Findings and Pain Symptoms as Potential Risk Factors for Chronic TMD: Descriptive Data and Empirically Identified Domains from the OPPERA Case-Control Study. J. Pain 2011, 12, T27-T45. [CrossRef]

19. Slade, G.D.; Ohrbach, R.; Greenspan, J.D.; Fillingim, R.B.; Bair, E.; Sanders, A.E. Painful Temporomandibular Disorder: Decade of Discovery from OPPERA Studies. J. Dent. Res. 2016, 95, 1084-1092. [CrossRef]

20. Okeson, J.P. Management of Temporomandibular Disorders and Occlusion, 8th ed.; Elsevier: St. Louis, MI, USA, 2020.

21. Okeson, J.P. The Classification of Orofacial Pains. Oral Maxillofac. Surg. Clin. N. Am. 2008, 20, 133-144. [CrossRef]

22. Henrikson, T.; Nilner, M. Temporomandibular disorders and the need for stomatognathic treatment in orthodontically treated and untreated girls. Eur. J. Orthod. 2000, 22, 283-292. [CrossRef]

23. Proffit, W.R. Contemporary Orthodontics, 6th ed.; Elsevier: Philadelphia, IL, USA, 2018.

24. Greene, C.S.; Galang-Boquiren, M.T.S.; Bartilotta, Y. Orthodontics and the temporomandibular joint: What orthodontic providers need to know. Quintessence Int. 2017, 48, 799-808.

25. Armijo-Olivo, S.; Silvestre, R.; Fuentes, J.; Da Costa, B.R.; Gadotti, I.C.; Warren, S.; Major, P.W.; Thie, N.M.; Magee, D.J. Electromyographic Activity of the Cervical Flexor Muscles in Patients with Temporomandibular Disorders While Performing the Craniocervical Flexion Test: A Cross-Sectional Study. Phys. Ther. 2011, 91, 1184-1197. [CrossRef] [PubMed]

26. Armijo-Olivo, S.; Silvestre, R.A.; Fuentes, J.P.; da Costa, B.R.; Major, P.W.; Warren, S. Patients With Temporomandibular Disorders Have Increased Fatigability of the Cervical Extensor Muscles. Clin. J. Pain 2012, 28, 55-64. [CrossRef] [PubMed]

27. Armijo Olivo, S.; Magee, D.J.; Parfitt, M.; Major, P.; Thie, N.M.R. The association between the cervical spine, the stomatognathic system, and craniofacial pain: A critical review. J. Orofac. Pain 2006, 20, 271-287. [PubMed] 
28. Stiesch-Scholz, M.; Fink, M.; Tschernitschek, H. Comorbidity of internal derangement of the temporomandibular joint and silent dysfunction of the cervical spine. J. Oral Rehabil. 2003, 30, 386-391. [CrossRef]

29. Bogduk, N.; Govind, J. Cervicogenic headache: An assessment of the evidence on clinical diagnosis, invasive tests, and treatment. Lancet Neurol. 2009, 8, 959-968. [CrossRef]

30. Bartsch, T. Stimulation of the greater occipital nerve induces increased central excitability of dural afferent input. Brain 2002, 125, 1496-1509. [CrossRef]

31. Bartsch, T. Increased responses in trigeminocervical nociceptive neurons to cervical input after stimulation of the dura mater. Brain 2003, 126, 1801-1813. [CrossRef]

32. Goadsby, P.; Bartsch, T. Introduction: On the Functional Neuroanatomy of Neck Pain. Cephalalgia 2008, 28, 1-7. [CrossRef]

33. D'Attilio, M.; Filippi, M.R.; Femminella, B.; Festa, F.; Tecco, S. The Influence of an Experimentally-Induced Malocclusion On Vertebral Alignment in Rats: A Controlled Pilot Study. CRANIO 2005, 23, 119-129. [CrossRef]

34. McGuinness, N.J.; McDonald, J.P. Changes in natural head position observed immediately and one year after rapid maxillary expansion. Eur. J. Orthod. 2005, 28, 126-134. [CrossRef]

35. Motoyoshi, M.; Shimazaki, T.; Sugai, T.; Namura, S. Biomechanical influences of head posture on occlusion: An experimental study using finite element analysis. Eur. J. Orthod. 2002, 24, 319-326. [CrossRef]

36. La Touche, R.; Fernández-De-Las-Peñas, C.; Fernández-Carnero, J.; Escalante, K.; Angulo-Díaz-Parreño, S.; Paris-Alemany, A. The effects of manual therapy and exercise directed at the cervical spine on pain and pressure pain sensitivity in patients with myofascial temporomandibular disorders. J. Oral Rehabil. 2009, 36, 644-652. [CrossRef]

37. De Laat, A.; Meuleman, H.; Stevens, A.; Verbeke, G. Correlation between cervical spine and temporomandibular disorders. Clin. Oral Investig. 1998, 2, 54-57. [CrossRef]

38. Friedman, M.H.; Weisberg, J. The craniocervical connection: A retrospective analysis of 300 whiplash patients with cervical and temporomandibular disorders. CRANIO 2000, 18, 163-167. [CrossRef]

39. Gil-Martínez, A.; Grande-Alonso, M.; López-De-Uralde-Villanueva, I.; López-López, A.; Fernández-Carnero, J.; La Touche, R. Chronic Temporomandibular Disorders: Disability, pain intensity and fear of movement. J. Headache Pain 2016, 17, 1-9. [CrossRef]

40. Cuenca-Martínez, F.; Herranz-Gómez, A.; Madroñero-Miguel, B.; Reina-Varona, Á.; La Touche, R.; Angulo-Díaz-Parreño, S.; Pardo-Montero, J.; Del Corral, T.; López-De-Uralde-Villanueva, I. Craniocervical and Cervical Spine Features of Patients with Temporomandibular Disorders: A Systematic Review and Meta-Analysis of Observational Studies. J. Clin. Med. 2020, 9, 2806. [CrossRef] [PubMed]

41. Saddu, S.C.; Dyasanoor, S.; Valappila, N.J.; Ravi, B.V. The Evaluation of Head and Craniocervical Posture among Patients with and without Temporomandibular Joint Disorders-A Comparative Study. J. Clin. Diagn. Res. 2015, 9, ZC55-8. [CrossRef] [PubMed]

42. da Costa, D.R.A.; de Lima Ferreira, A.P.; Pereira, T.A.B.; Porporatti, A.L.; Conti, P.C.R.; Costa, Y.M. Neck disability is associated with masticatory myofascial pain and regional muscle sensitivity. Arch. Oral Biol. 2015, 60, 745-752. [CrossRef] [PubMed]

43. Fernández-De-Las-Peñas, C.; Galán-Del-Río, F.; Alonso-Blanco, C.; Jiménez-García, R.; Arendt-Nielsen, L.; Svensson, P. Referred Pain from Muscle Trigger Points in the Masticatory and Neck-Shoulder Musculature in Women With Temporomandibular Disoders. J. Pain 2010, 11, 1295-1304. [CrossRef]

44. Flores, H.F.; Ottone, N.E.; Fuentes, R. Analysis of the morphometric characteristics of the cervical spine and its association with the development of temporomandibular disorders. CRANIO 2016, 35, 1-7. [CrossRef]

45. Grondin, F.; Hall, T.; Ella, B.; Laurentoye, M.; Laurentjoye, M. Upper cervical range of motion is impaired in patients with temporomandibular disorders. CRANIO 2014, 33, 91-99. [CrossRef] [PubMed]

46. Pallegama, R.W.; Ranasinghe, A.W.; Weerasinghe, V.S.; Sitheeque, M.A.M. Influence of masticatory muscle pain on electromyographic activities of cervical muscles in patients with myogenous temporomandibular disorders. J. Oral Rehabil. 2004, 31, 423-429. [CrossRef] [PubMed]

47. Silveira, A.; Armijo-Olivo, S.; Gadotti, I.C.; Magee, D. Masticatory and cervical muscle tenderness and pain sensitivity in a remote area in subjects with a temporomandibular disorder and neck disability. J. Oral Facial Pain Headache 2014, 28, 138-146. [CrossRef] [PubMed]

48. Gomes, L.; Horta, K.O.C.; Goncalves, J.R.; Santos-Pinto, A. Systematic Review: Craniocervical posture and craniofacial morphology. Eur. J. Orthod. 2014, 36, 55-66. [CrossRef]

49. Joy, T.E.; Tanuja, S.; Pillai, R.R.; Manchil, P.R.D.; Raveendranathan, R. Assessment of craniocervical posture in TMJ disorders using lateral radiographic view: A cross-sectional study. CRANIO 2019, 1-7, 1-7. [CrossRef]

50. Crawford, S.D. Condylar axis position, as determined by the occlusion and measured by the CPI instrument, and signs and symptoms of temporomandibular dysfunction. Angle Orthod. 1999, 69, 115-116.

51. Wood, D.P.; Elliott, R.W. Reproducibility of the centric relation bite registration technique. Angle Orthod. 1994, 64, 211-220.

52. Alexander, S.R.; Moore, R.N.; DuBois, L.M. Mandibular condyle position: Comparison of articulator mountings and magnetic resonance imaging. Am. J. Orthod. Dentofac. Orthop. 1993, 104, 230-239. [CrossRef]

53. Chisnoiu, A.M.; Picos, A.M.; Popa, S.; Chisnoiu, P.D.; Lascu, L.; Picos, A.; Chisnoiu, R. Factors involved in the etiology of temporomandibular disorders-A literature review. Med. Pharm. Rep. 2015, 88, 473-478. [CrossRef]

54. Magnusson, T.; Egermarki, I.; Carlsson, G.E. A prospective investigation over two decades on signs and symptoms of temporomandibular disorders and associated variables. A final summary. Acta Odontol. Scand. 2005, 63, 99-109. [CrossRef] 
55. McNamara, J.A.; Seligman, D.A.; Okeson, J.P. Occlusion, Orthodontic treatment, and temporomandibular disorders: A review. J. Orofac. Pain 1995, 9, 73-90. [PubMed]

56. Pullinger, A.; Seligman, D.; Gornbein, J. A Multiple Logistic Regression Analysis of the Risk and Relative Odds of Temporomandibular Disorders as a Function of Common Occlusal Features. J. Dent. Res. 1993, 72, 968-979. [CrossRef] [PubMed]

57. Weffort, S.Y.K.; de Fantini, S.M. Condylar displacement between centric relation and maximum intercuspation in symptomatic and asymptomatic individuals. Angle Orthod. 2010, 80, 835-842. [CrossRef]

58. Meiyappan, N.; Tamizharasi, S.; Senthilkumar, K.P.; Janardhanan, K. Natural head position: An overview. J. Pharm. Bioallied Sci. 2015, 7, S424-S427. [CrossRef]

59. Vion, P.E. Anatomia Cefalométrica, 2nd ed.; Livraria Santos: São Paulo, Brazil, 2002.

60. Rocabado, M. Analisis biomecánico cráneocervical a través de una teleradiografia lateral. Rev. Chil. Ortod. 1984, 1, 42-52.

61. Gregoret, J.; Tuber, E.; Escobar, L.; Matos da Fonseca, A. Ortodoncia y Cirugia Ortognática: Diagnóstico y Planificación; AMOLCA: Medellín, Colombia, 2014.

62. Graber, L.W.; Vanarsdall, R.L.; Vig, K.W.L. Orthodontics: Current Principles and Techniques; Elsevier/Mosby: Philadelphia, PA, USA, 2012.

63. Sonnesen, L.; Bakke, M.; Solow, B. Temporomandibular disorders in relation to craniofacial dimensions, head posture and bite force in children selected for orthodontic treatment. Eur. J. Orthod. 2001, 23, 179-192. [CrossRef]

64. Solow, B.; Tallgren, A. Head posture and craniofacial morphology. Am. J. Phys. Anthr. 1976, 44, 417-435. [CrossRef]

65. Portney, L.G.; Watkins, M.P. Foundations of Clinical Research: Applications to Practice, 3rd ed.; Pearson/Prentice Hall: Upper Saddle River, NJ, USA, 2009.

66. Field, A. Discovering Statistics Using SPSS: And Sex and Drugs and Rock 'N' Roll, 4th ed.; Sage: London, UK, 2013.

67. von Piekartz, H. Craniofacial Pain: Neuromusculoskeletal Assessment, Treatment and Management; Elsevier Health Sciences: Philadelphia, PA, USA, 2007.

68. Cavanaugh, J.M. Pain Generation in Lumbar and Cervical Facet Joints. J. Bone Jt. Surg. Am. 2006, 88, 63.

69. Littlewood, S.J. Evidence-based retention: Where are we now? Semin. Orthod. 2017, 23, 229-236. [CrossRef]

70. Littlewood, S.J.; Kandasamy, S.; Huang, G. Retention and relapse in clinical practice. Aust. Dent. J. 2017, 62, 51-57. [CrossRef]

71. Kraus, S. Temporomandibular Disorders, Head and Orofacial Pain: Cervical Spine Considerations. Dent. Clin. N. Am. 2007, 51, 161-193. [CrossRef] [PubMed]

72. Okeson, J.P. Evolution of occlusion and temporomandibular disorder in orthodontics: Past, present, and future. Am. J. Orthod. Dentofac. Orthop. 2015, 147, S216-S223. [CrossRef] [PubMed]

73. Pinho, T.; Pacheco, J.J.; Salazar, F. Treatment of an asymmetric malocclusion: A case report. Aust. Orthod. J. 2014, 30, 72-80.

74. Klobas, L.; Gambardella, U.; Hansson, T.L. A 5-Year Follow-Up of Temporomandibular Disorder Treatment Emphasizing Condylar Asymmetry. CRANIO 2006, 24, 265-273. [CrossRef] [PubMed]

75. Ishizaki, K.; Suzuki, K.; Mito, T.; Tanaka, E.M.; Sato, S. Morphologic, functional, and occlusal characterization of mandibular lateral displacement malocclusion. Am. J. Orthod. Dentofac. Orthop. 2010, 137, 454.e1-454.e9. [CrossRef]

76. Pinho, T.; Figueiredo, A. Orthodontic-orthognathic surgical treatment in a patient with Class II subdivision malocclusion: Occlusal plane alteration. Am. J. Orthod. Dentofac. Orthop. 2011, 140, 703-712. [CrossRef]

77. Pinho, T.; Neves, M.; Alves, C. Multidisciplinary management including periodontics, orthodontics, implants, and prosthetics for an adult. Am. J. Orthod. Dentofac. Orthop. 2012, 142, 235-245. [CrossRef] [PubMed]

78. Pinho, T. Treatment of a Class II subdivision based on occlusal plane control: A clinical case. Orthod. Art Pr. Dentofac. Enhanc. 2012, 13, 128-137.

79. de Farias Neto, J.P.; de Santana, J.M.; de Santana-Filho, V.J.; Quintans-Junior, L.J.; de Lima Ferreira, A.P.; Bonjardim, L.R. Radiographic measurement of the cervical spine in patients with temporomandibular dysfunction. Arch. Oral Biol. 2010, 55, 670-678. [CrossRef]

80. Hong, S.W.; Lee, J.K.; Kang, J.-H. Relationship among Cervical Spine Degeneration, Head and Neck postures, and Myofascial Pain in Masticatory and Cervical Muscles in Elderly with Temporomandibular Disorder. Arch. Gerontol. Geriatr. 2019, 81, 119-128. [CrossRef] 